\title{
EPISTEMOLOGIAS DO SUL APLICADAS NO CONTROLE CONCENTRADO DE CONSTITUCIONALIDADE BRASILEIRO ${ }^{1}{ }^{2} 2$
}

\section{EPISTEMOLOGIES OF THE SOUTH APPLIED IN THE BRAZILIAN CONTROL OF CONSTITUTIONALITY}

\author{
Wagner Vinicius de Oliveira ${ }^{3}$
}

Data de recebimento: $21 / 02 / 2018$

Data de Aprovação: 15/09/2018

\section{RESUMO}

Nesse artigo, traça-se as linhas iniciais para a possível alteração do estado de coisas conhecido como "colonialidade do saber" aplicado no controle de constitucionalidade brasileiro. O primeiro passo é compreender que o fenômeno jurídico na contemporaneidade exige as participações sociais, nesse sentido o foco recai sobre a aproximação entre o pensamento decolo-

1 Este artigo é um dos produtos da pesquisa de mestrado acadêmico em direito desenvolvida junto à Universidade Federal de Uberlândia - UFU (2017-2018), na qualidade de bolsista pela Coordenação de Aperfeiçoamento de Pessoal de Nível Superior - CAPES. Trata-se de uma versão inédita completa, atualizada e revisitada da apresentação homônima (comunicação oral e resumo publicado em anais de congressos) realizada durante o III Congresso de Direito Constitucional e Filosofia Política: a desigualdade e a reconstrução da democracia social, realizado no período de 24 a 27 de outubro de 2017, na cidade de Curitiba/PR. Cf. OLIVEIRA, Wagner Vinicius de; SOUSA, Jaqueline Aparecida Fernandes. Epistemologias do sul aplicada ao controle concentrado de constitucionalidade brasileiro. In: BUSTAMANTE, Thomas da Rosa de. et al. (Coord.). Anais do III Congresso de Direito Constitucional e Filosofia Política: a desigualdade e a reconstrução da democracia social. [Caderno de resumos]. Belo Horizonte: Arraes, 2017, p. 177-179.

2 Agradece-se ao Prof. Dr. André Fabiano Voigt, a época integrante do Instituto de História da UFU, pelas reflexões e indicações bibliográficas realizadas durante as aulas na disciplina História, Hermenêutica e Estética, ministradas no Programa de Pós-Graduação em História (mestrado/doutorado) da UFU, durante o segundo semestre de 2017. Igualmente, agradece-se aos(as) dois(duas) avaliadores(as) anônimos(as). 
nial e o sentido material da Constituição. Para tanto, essa pesquisa bibliográfica serve-se do método de análise documental com o objetivo de investigar as condições de possibilidades oferecidas pelas epistemologias do Sul para o controle de constitucionalidade brasileiro. Os resultados obtidos apontam para uma inclusão epistemológica de saberes outros numa outra racionalidade, democrática e inclusiva, bem por isso, sugere-se a virada de compreensão anunciada no título do presente artigo. Em conclusão, vê-se que o hemisfério Sul, do lado ocidental do mundo, se encontra permeado (dependente) das interpretações que, de outra sorte, deveriam ser suas.

\section{PALAVRAS-CHAVE}

América Latina. Jurisdição constitucional. Pensamento decolonial. Virada epistemológica.

\section{ABSTRACT}

In this article, we have designed the initial lines for the possible alteration of the state of things known as "coloniality of knowledge" applied in the Brazilian control of constitutionality. The first step is to understand that the juridical phenomenon in the contemporaneity demands by the social participations, in this sense the focus falls to approach between on decolonial thinking and the material sense of the Constitution. For this, we used in this bibliographic research the method of documentary analysis with the objective of investigating the conditions of possibilities offered by the epistemologies of the South for the Brazilian constitutionality control. The results obtained point to an epistemological inclusion of other knowledge for a rationality other, democratic and inclusive, well for that reason; we suggest the understanding turn in the title of the present article. In conclusion, we have that the south hemisphere, of the western side of the world, is permeated (dependent) on interpretations that, otherwise, should be its own.

\section{KEYWORDS}

Latin America. Constitutional jurisdiction. Decolonial thinking. Epistemological turning. 


\section{INTRODUÇÃO}

Nesse ensaio busca-se articular algumas propostas para a democratização do controle de constitucionalidade a partir da dicotomia teleológica existente no controle concentrado de constitucionalidade brasileiro. A dita clivagem finalística encontra-se presente na distinção entre a prevalência na salvaguarda das "razões do Estado" 4 ou da tutela dos direitos e garantias fundamentais, que, em alguma medida, deve ser creditada na conta das orientações epistemológicas de interpretação e aplicação do direito. Mas, por certo, como diria Gadamer (2015), não deve haver diferenciação entre as instâncias da interpretação ou compreensão e da aplicação.

Concretamente se investiga as possibilidades oferecidas pelas epistemologias do Sul para a inserção das participações sociais no controle de constitucionalidade brasileiro. Tal incursão teórica justifica-se, basicamente, por dois motivos: primeiro, por ser dotada de relevância social, na medida em que amplia a argumentação substancial com eventual aprimoramento do controle de constitucionalidade; segundo, porque pretende contribuir com a tarefa acadêmica de desvelar o mito de que a simples transposição de ideias estrangeiras per se forneçam as soluções adequadas (acertadas e factíveis) para o sistema jurídico brasileiro.

Portanto, as redefinições proposta pela diversidade epistemológica justificam a inclusão de diálogos multiculturais. Para essa empreitada, elege-se como abordagem teórico-metodológica a análise documental implicada com as reflexões da colonialidade, isto é, o "[...] padrão de poder que opera através da naturalização de hierarquias territoriais, raciais, culturais e epistêmicas, possibilitando a reprodução de relações de dominação;" (RESTREPO; ROJAS, 2010, p. 15, tradução nossa). ${ }^{5}$

Deste modo, estabelece-se como hipótese a ser trabalhada que as con-

${ }^{4}$ Cf. BORGES, Alexandre Walmott; CÂMARA, Fabiana Angélica Pinheiro; VILLAROEL, Ivette Esis. O sistema de controle de constitucionalidade brasileiro: entre a tutela de direitos e a tutela do ordenamento. In: Robl Filho, Ilton Norberto; Scheleder, Adriana Fasolo Pilati. (Org.). Jurisdição constitucional e democracia. Itajaí: Univali, 2016, p. 138-164.

${ }^{5}$ No original: "[...] patrón de poder que opera a través de la naturalización de jerarquías territoriales, raciales, culturales y epistémicas, posibilitando la re-producción de relaciones de dominación;" (RESTREPO; ROJAS, 2010, p. 15). 
dições de emergência, existência e transformação da atualidade encontram-se indissociavelmente interligadas à tese da colonialidade como uma exterioridade constitutiva. $\mathrm{O}$ nexo que se pretende estabelecer é a compatibilidade entre o objeto de análise (controle de constitucionalidade brasileiro) e as matrizes epistemológicas latino-americanas, com vistas a analisar o provável impacto na (re)orientação de uma nova "engenharia constitucional" brasileira (CERQUEIRA NETO; SALGADO, 2016, p. 116).

Algumas coisas precisam ser ditas. Nem de longe, se cogita a ingênua resposta de unidade do "pensamento latino-americano" ou de uma "panaceia capaz de curar, sozinha e definitivamente, todos os males". Ao contrário, o ambiente latino-americano é uma zona instável de constantes avanços e retrocessos, que, no mínimo, merece análises mais detidas. Considerações análogas podem ser levantadas para os ditos "pensamentos hegemônicos".

Feitas as apresentações, este artigo será composto por seis partes. Afora as partes introdutória, de considerações finais e de bibliografia esse artigo desenvolve-se em três eixos. No primeiro tópico constata-se a existência de um fenômeno que possui distintas nomenclaturas, tais como: "eurocentrismo", "zona colonial", "monoculturalismo autoritário", dentre outras possibilidades, que na essência representam a atualização da dicotomia entre a metrópole e a colônia. A par disso, em sequência esboça-se uma racionalidade democrática e inclusiva de saberes outros para fundamentar a possível superação dessa estrutura binária.

Por fim, no terceiro tópico, faz-se um recorte específico sobre o controle de constitucionalidade brasileiro, com o objetivo de (re)orientar-se pelo sentido material da Constituição que, por sua vez, observa e orienta o modo de ser de um povo em determinado tempo e território. Tal inserção também será realizada pelas participações sociais ao possibilitar diálogos frontais com a tutela dos direitos e das garantias fundamentais, pela sobredita espécie de jurisdição constitucional, a partir do intercâmbio de algumas ideias existentes na América Latina.

No entanto, isto não significa que este artigo não contará com as reflexões teóricas de matrizes norte-americanas ou europeias, mas, de outra sorte, devem ser contrastadas com as realidades vivenciadas no contexto brasileiro. 
Longe de representar uma espécie de "purismo" latino-americano, sob pena de incorrer no "sectarismo teórico" (DUSSEL, [1977], p. 211), mas, traçar as linhas iniciais de um estudo comparativo sobre teorias cujos contextos e realidades sociais aproximem-se das realidades enfrentada pelo controle de constitucionalidade brasileiro.

\section{PENSAMENTOS LATINO-AMERICANOS COMO POSSÍVEL PARADIGMA DE DESCONSTRUÇÃO HISTÓRICA}

De saída, afirma-se que o colonial não permanece circunscrito a um período histórico pretérito, no sentido cronológico-temporal do termo, mas, de outra sorte, se revela como uma questão que permanece atual. ${ }^{6} \mathrm{O}$ pensamento colonial, emerge enquanto um dos produtos do processo binário fincado em argumentos de autoridade eurocêntricos, é capaz de condicionar as variadas relações sociais (humanas) dentro dos eixos do "desenvolvimento" ou do "subdesenvolvimento". No entanto, essas categorias são primariamente reflexos das questões geopolíticas que reverberam na contemporaneidade.

Esse movimento global, entendido a partir de uma série de pensamentos que operam por distintas maneiras; notadamente nos aspectos acadêmicos, científicos, econômicos, militares, políticos, religiosos, tecnológicos, dentre outros. De certa forma, os traços de uma teoria política etnocêntrica ultrapassam as sobreditas caraterísticas e, ante a insuficiência de espaço para desenvolvê-las aqui, muito embora sejam trabalhadas de modo transversal, elege-se a feição epistemológica para o exame nas páginas que se seguem.

Constata-se, portanto, que a "colonialidade do poder" (FIGUEIREDO, 2017, p. 91) produz a "colonialidade do saber" (RESTREPO; ROJAS, 2010, p. 26). Por outras palavras, existem hegemonias políticas e econômicas que desembocam numa hegemonia científica, “Ora, a equação é simples:", conforme demonstra Magalhães (2016, p. 14), "se eu posso dizer o que é a

\footnotetext{
${ }^{6}$ Ainda hoje a França possui 10 (dez) Departamentos e Regiões de Outros Mares (Départements et Régions d'Outre-Mer DROM), quais sejam: la Polynésie française Thahiti, Saint-Pierre-et-Miquelon, Saint-Martin Saint-Barthélemy, la Guadaloupe, le Guyane, la Martinique, Mayotte, la Réunion, Wallis-et-Futuna e la Nouvelle-Calédonie (BERTHET, et. al. 2012, p. 120).
} 
ciência, logo, ciência, será aquilo o faço, e não ciência o que o outro 'eles' subalternizados fazem."

Antes, porém, fala-se em um helenocentrismo originário como fonte histórico-filosófica de produção daquilo que Pazello (2016, p. 212) chama de eurocentrismo; que por sua vez, se manifesta pela imposição - as vezes velada, outras nem tanto - das chamadas "realidades geopoliticamente universalizadas". De fato, tem-se desníveis nas oportunidades de produção e divulgação do conhecimento científico, que somados as pretensões, sabidamente falsas, de universalidade dos pensamentos hegemônicos colaboram para a produção do mencionado fenômeno. Isto é, a partir de pressupostos não verificáveis, ou constatados apenas à luz das matrizes dominantes, se estabelecem relações de causalidade que menosprezam ou anulam os conhecimentos disseminados fora das supostas "zonas de excelência" mundial.

Dentro dessa visão politicamente orientada, as origens históricas das forças produtivas ditas mundiais impõem o fato de que uns poucos Estados subjuguem outros. E, como consequência, se há uma diminuta parcela dominante deve existir uma vasta "zona colonial" (SANTOS, 2009, p. 26), até mesmo como forma de perpetuar a força dessa tradição que se renova em diferentes tempos e espaços. Cambi (2009, p. 75, grifo do autor), retrata essa mesma situação sob outro aspecto:

[...] o monoculturalismo autoritário que não reconhece a existência de outras culturas senão a dos povos colonizadores, ignorando ou colocando em um lugar de inferioridade a cultura dos povos colonizados (v.g. o conhecimento indígena e afrodescendente na América Latina e o camponês da África).

Segundo Dussel ([1977], p. 76), “[...] podemos descobrir que há um sistema mundial cujo centro é os Estados Unidos, e com interdependência relativa a Europa, o Japão e o Canadá. O resto é periferia [...]". Nessa perspectiva, reporta-se ao tema presente não apenas na América Latina, mas, de alguma forma, nos países não pertencentes ao seleto grupo hegemônico, ou seja, parcela do continente europeu e os Estados Unidos da América, ou pela junção de ambos, como diria Bonavides (2001, p. 33), os "Estados Unidos da Europa". 
Em sentido contrário, tem-se uma "ética de intersubjetividade crítica", que implica conhecimento e reconhecimento da existência e da necessidade de entrecruzar distintos saberes e ignorâncias não originários das fontes tradicionais. Sob o mesmo ponto de vista, Pazello (2016, p. 212, tradução nossa), ${ }^{7}$ define esse movimento como sendo:

A descolonialidade do poder e do saber através do protagonismo dos movimentos populares, como classe popular organizada, inspira a crítica jurídica que com eles se solidariza, especialmente sobre a práxis das assessorias jurídicas populares, sejam académicas, de advogados, políticas e pedagógicas junto a tais movimentos.

Junto as linhas acima transcritas faz-se a leitura de que a necessidade social dos povos da América Latina reclama uma abordagem diferenciada e aproximativa de suas realidades materiais emergentes. Daí a necessidade de compreensão do conceito substantivo de Constituição, que será trabalhado mais a frente, até mesmo como forma aproximativa dessa realidade que subjaz ignorada em sua esmagadora maioria pelos(as) teóricos(as) e por suas teorias.

A reiteração da história hegemônica provoca, simultaneamente, a incorporação acrítica de conceitos importados e a leitura deficitária da realidade na qual se encontra inserido(a), além de reforçar a invisibilidade dos saberes que destoam daqueles produzidos nos centros dominantes. Contudo, a tarefa ora empreendida não se trata de "descobrir ou inventar" o autêntico conhecimento latino uma vez que a própria ideia de América foi uma invenção europeia concebida à revelia dos povos e nações originários. Ao contrário, mediante o ecletismo teórico "[...] assumir uma postura descolonial na produção do conhecimento" (FIGUEIREDO, 2017, p. 79), para passar e ultrapassar as fronteiras Norte e Sul - imagens demasiadamente abstratas - tornando possível que as produções intelectuais não permaneçam restritas a determinados territórios.

\footnotetext{
${ }^{7}$ No original: "La descolonialidad del poder y del saber a través del protagonismo de los movimientos populares, como clase popular organizada, inspira a la crítica jurídica que con ellos se hermana, especialmente si sopla en la praxis de las asesorías jurídicas populares, ya sean académicas, de abogados, políticas y pedagógicas junto a tales movimientos." (PAZELLO, 2016, p. 212).
} 
Esse paradigma forjado por séculos a fio, para além da negativa de reconhecimento de outras maneiras de conhecer, de certa forma, condiciona a esquecer ou desconsiderar, por completo, a existência do Sul. Nesse cenário,

Em linhas gerais, exploração e dominação sempre foram a razão do "ser latino-americano". Tanto que habita no senso comum uma velada crença de que as ideias do exterior necessitam ser copiadas, reproduzidas e aqui aplicadas, fruto dos longos anos de cabresto cultural e econômico imposto principalmente pelo mundo europeu. (CAMARGO; GABIATTI; MELLO, 2013, p. 423-424).

Essa tensa e conflituosa relação é reforçada pelo período de reestruturação da Segunda Guerra Mundial, embora nem tão mundial tenha sido, uma vez que um evento de proporção mundial, com efeito, ultrapassa os agentes envolvidos nesse conflito armado. Seria, então, adequado pensar em uma guerra (ou guerras: primeira e segunda) com repercussões por todo o mundo, mas não mundial. De acordo com os sobreditos autores, persiste a ideia do “[...] centro irradiador de conhecimento, até mesmo porque, após o processo de reestruturação do pós-guerra, manteve no europeu a sua identidade e consciência de sua capacidade - e necessidade - de impor sua cultura e seu modo de pensar ao resto do mundo." (CAMARGO; GABIATTI; MELLO, 2013, p. 429).

Dessa maneira, torna-se conflituosa a desvalorização do "restante" do mundo. Com isso não se furta em reconhecer as contribuições que o "antigo continente" proporcionou, proporciona e, certamente, proporcionará ao mundo, todavia, cumpre também desvelar os pensamentos autênticos produzidos em outros eixos epistemológicos, notadamente na América Latina. Do contrário, prevalecerá a “[...] posição de inferioridade com relação à produção de conhecimento eurocêntrica, que contribui para a manutenção do poder nas mãos de poucos em detrimento de expressiva parcela da população que fica a (sic) mercê da própria sorte." (CAMARGO; GABIATTI; MELLO, 2013, p. 432). Segundo indicado por Pazello (2016, p. 208-209), uma tentativa de superação do paradigma procedimental, ainda prevalente no direito, é fornecida pelas críticas no que toca à sua historicidade; pela compreensão do direito en- 
quanto espécie do gênero de organização política; também pela superação do formalismo jurídico e, por fim, mediante a afirmação histórica de um direito insurgente.

A proposta apresentada será um "mergulho" nos pensamentos latino -americanos para que se alcance a tonalidade adequada para as questões que lhes são peculiares. O primeiro passo é a compreensão daquilo que “[...] habita no senso comum uma velada crença de que as ideias do exterior necessitam ser copiadas, reproduzidas e aplicadas aqui, no Brasil. [...] mas é notória a escassez de teorias jurídicas de base criadas a partir do efetivo contexto social brasileiro." (CAMARGO; GABIATTI; MELLO, 2013, p. 432-433).

Pela absorção acrítica de teorias estrangeiras que, voluntária ou involuntariamente, ignoram os conhecimentos não produzidos nas "metrópoles" do mundo, produzem uma espécie de aculturação social. Ao que tudo indica, conforme apontam Camargo, Gabiatti e Mello (2013, p. 432), “São obras produzidas a ritmo industrial, plastificadas, que por nascerem nessa redoma nada mais conseguem fazer do que a reproduzir, recontando-a mimeticamente." Por outro lado, teorias estrangeiras são pensadas e elaboradas para uma dada realidade social, cultural, institucional que encontrará dificuldades de reprodução fora de seu contexto original. Evidentemente, não se trata apenas de uma questão política ou ideológica.

Frise-se que "Essa concentração intelectual cumpre um duplo papel: manter o poder, por um lado, e reconstruir os mecanismos de dominação, por outro." (CAMARGO; GABIATTI; MELLO, 2013, p. 434). Os autores afirmam ainda que para além do propósito da aparente incorporação epistêmica "[...] auxilia na manutenção da barreira ao nascimento de um pensar jurídico autêntico na América Latina." (CAMARGO; GABIATTI; MELLO, 2013, p. 436).

Em contraposição, "[...] um direito mais aproximado da realidade latino-americana. [...] oferecendo condições para propor pontos de transformação mais eficazes e adequados às reais condições dos processos sociais na América Latina." (CAMARGO; GABIATTI; MELLO, 2013, p. 440). Deve-se demonstrar que as concepções jurídicas centradas nas análises formais, tanto dos textos normativos, quanto das formas de conhecê-lo (epistemologias), implica conjugar as análises de ordem material e formal. 
Importa ressaltar a desnecessidade entre a "[...] disputa epistemológica moderna entre as formas científicas e não-científicas de verdade" (SANTOS, 2009 , p. 25). Pois, do contrário ter-se-ia a continuidade da mentalidade hegemônica demarcada pela dicotomia metrópole versus colônia. Com isso, quer-se colocar em movimento uma tentativa de demonstrar que para a superação maniqueísta importa reconhecer e valorizar noções epistêmicas que se encontram deslocadas do eixo geográfico tradicional.

Determinados setores particulares do conhecimento tradicional, cuja pretensão ou interpretação de universalidade e de atemporalidade que fazem de si próprios tendem a impor, conforme Santos (2009, p. 31), as “[...] linhas abissais [que] continuam a estruturar o conhecimento e o direito modernos e que são constitutivas das relações e interacções (sic) políticas e culturais que o Ocidente protagoniza no interior do sistema mundial."

Antes, porém, deve-se distinguir, em termos de conhecimento e de reconhecimento, "o metropolitano do colonial" (SANTOS, 2009, p. 41). Isso se deve não apenas em termos dicotômicos dos muitos já existentes, mas, para que outras vozes possam ecoar deve-se compreender a existência de "vozes majoritárias" que ecoam livre e soberanamente silenciando todas as demais. ${ }^{8}$ Mesmo porque, não há como propor a paridade de discursos argumentativos uma vez que se desconhece as epistemologias não albergadas no eixo comum. Portanto, "É preciso um novo pensamento", afirma Santos (2009, p. 41), "um pensamento pós-abissal."

Para Santos (2009, p. 33), há de existir um movimento de cognição e de consideração do Sul, ou simplesmente epistemologias do Sul, como uma resposta viável e necessária, contudo, insuficiente para assegurar o movimento chamado pelo autor de "cosmopolitismo subalterno", segundo suas palavras:

O cosmopolitismo subalterno manifesta-se através das iniciativas e movimentos que constituem a globalização contra-hegemónica (sic). Consiste num vasto conjunto de redes,

\footnotetext{
${ }^{8}$ Sobre o tema, entre outros conferir: FISS, Owen M. A ironia da liberdade de expressão: Estado, regulação e diversidade na esfera pública. Tradução e prefácio de Gustavo Binenbojm e Caio Mário da Silva Pereira Neto. Rio de Janeiro: Renovar, 2005; OLIVEIRA, Wagner Vinicius de. Resenha. FISS, Owen M. A ironia da liberdade de expressão: Estado, regulação e diversidade na esfera pública. Tradução e prefácio de Gustavo Binenbojm e Caio Mário da Silva Pereira Neto. Rio de Janeiro: Renovar, 2005. Revista da Faculdade de Direito (UFU), v. 44, 2016, p. 01-05.
} 
iniciativas, organizações e movimentos que lutam contra a exclusão económica, social, política e cultural [...] (SANTOS, 2009 , p. 42).

Ao seguir o rearranjo proposto, tem-se que "A ecologia de saberes baseia-se na ideia de que o conhecimento é interconhecimento" (SANTOS, 2009 , p. 45). Ainda sobre o tema, as múltiplas formas de compreensão tocante as relações entre os seres humanos no meio cultural, econômico, ético-social, jurídico, dentre outros, Santos (2009, p. 57) esclarece também que "A ecologia de saberes capacita-nos para uma visão mais abrangente daquilo que conhecemos, bem como do que desconhecemos, e também nos previne para que aquilo que não sabemos é ignorância nossa, não ignorância em geral."

Como resultado do conhecimento de saberes outros, não somente os de matriz hegemônica, tem-se a possibilidade de criação de espaços teóricos de várias localidades geográficas do globo terrestre, aproximando de algo que possa receber a substantivação de comunidade, de forma mais elaborada Santos (2009, p. 47), esclarece que a:

[...] vinculação da ciência moderna aos desígnios da dominação colonial e imperial, e onde outros conhecimentos não científicos e não-ocidentais prevalecem nas práticas quotidianas das populações. [...] A utopia do interconhecimento é aprender outros conhecimentos sem esquecer os próprios.

A constatação de que os eixos tradicionalmente hegemônicos possuam melhores condições, em termos tecnológicos e recursos financeiros, não deve, contudo, justificar a totalização das concepções epistemológicas pela flagrante evidência de que, como qualquer outra parte, possuem apenas parcela do conhecimento. Assim, "[...] deve dar-se preferência às formas de conhecimento que garantam a maior participação dos grupos sociais envolvidos na concepção, na execução, no controlo (sic) e na fruição da intervenção" (SANTOS, 2009, p. 51).

Então, resta, por fim, três orientações, a saber: “[...] aprender que existe o Sul; aprender a ir para o Sul; aprender a partir do Sul e com o Sul [...]" (SAN- 
TOS, 2010, p. 242), cujo desafio central é construir as condições para realizar a virada epistemológica ou giro decolonial ${ }^{9}$ nos pensamentos latino-americanos para a transposição do perpétuo caminhar atrás da vanguarda hegemônica.

\section{POR UMA RACIONALIDADE DEMOCRÁTICA E INCLUSIVA DAS PARTICIPAÇÕES SOCIAIS}

Ao se propor outra racionalidade duplamente qualificada de democrática e inclusiva não se ignora as contundentes críticas que recaem sobre o projeto de uma suposta "democracia" como forma de colonização global, sob contornos políticos e intelectuais. ${ }^{10}$ Por outro lado, as articulações entre epistemologias e realidades revelam-se necessárias para que as instituições (jurídicas, políticas e sociais), que se reivindicam democráticas, possam acomodar as diversidades existentes a partir das bases teóricas adequadas. Deve-se, contudo, esclarecer os fundamentos contidos na proposta do presente tópico.

Racionalidade democrática quer expressar a qualidade daquilo que pode ser coerente e racionalmente defensável, diverge, portanto, do mero extrato subjetivo, ao contrário, caracteriza-se como intersubjetivamente partilhável. Segundo o qual decorra suficiente explicação - lógica e substancial - relevante para a compreensão do "como" e principalmente do "porquê" os argumentos utilizados tenham chegado ao ponto em que são apresentados.

Igualmente, reclama que seus argumentos se coadunem com o Estado democrático de direito, ou seja, possam ser construídos ou refeitos por outros(as) atores(as). Conforme afirmam Godoy e Kozicki (2014, p. 1.112) “A argumentação é um procedimento intrinsecamente conectado à razão, a qual deve revelar-se desapaixonada e desinteressada."

Em que pese a clareza do adjetivo utilizado (inclusivo), corresponde a ideia de que para a mencionada tarefa devem concorrer as diversas linhagens

\footnotetext{
${ }^{9}$ Assim conforme afirmam Restrepo e Rojas (2010, p. 37), entende-se que os termos "decolonial" e "descolonial" são intercambiáveis.

${ }^{10}$ Sobre o tema, por todos, consultar: GÜVEN, Ferit. Decolonizing democracy: intersections of philosophy and postcolonial theory. London: Lexington Books, 2015.
} 
de pensamentos, sob pena de não fazer jus a imagem democrática. Na senda teórica, ao (re)visitar criticamente destacados conceitos do modelo de Estado democrático de direito, não com uma imposição do lado ocidental do mundo, ${ }^{11}$ mas porque "Dessa forma, evita-se a discricionariedade ou imposição das vontades/ decisões dos governantes e abre-se espaço para poder-se eleger coletivamente a melhor decisão, sobretudo por aqueles que serão diretamente afetados por ela" (GODOY; KOZICKI, 2014, p. 1.117).

Destarte, ao se conhecer e reconhecer as diversidades, num primeiro momento epistemológico, pretende formar comunidades de distintos(as) intérpretes e, democraticamente minorar as possibilidades para não prevalecer que “O sábio é clarividente: vê com absoluta claridade." (DUSSEL, [1977], p. 56), sobre os espaços dos pensamentos originários do Sul. Logo, a tessitura do mundo com os fios do pensamento europeu implica apartar "os(as) não-esclarecidos(as)", relegando-os(as), portanto, ao ostracismo.

Numa perspectiva epistemológica inclusiva, insere-se a proposta de se conectar a América Latina, para o processo de difusão das outras concepções de mundo na compreensão política do real. Essa capacidade de leitura fornece o tom das realidades latentes nem sempre contempladas pelas análises hegemônicas. O conhecimento inclusivo possibilita formar outras visões de mundo, mediante a consciência de formas culturais diversas de uma ideologia dominante, pois, certos problemas somente se apresentam como tal em determinados contextos sociais.

Em certo sentido, trazem os reflexos de uma "missão civilizatória" que fornece um importante inventário sobre o espaço que determinadas culturas ocupam no mundo, produto, também, de um processo histórico composto pela Europa e pelos Estados Unidos da América, supostamente, pensantes e proprietários do pensamento moderno. Ao contrário, a tese ora esboçada é de que outras histórias precisam ser visibilizadas. Para se tornar compreensivas as dimensões com as quais se pretende estabelecer diálogos frontais, fala-se em tomar contato com as epistemologias produzidas na América Latina, América

\footnotetext{
${ }^{11}$ Conforme afirma Dussel (1980, p. 38-39): "Todavia, aceitam ingenuamente que sua cultura, seu poder político, o domínio de seus exércitos é justo; expande por toda a terra a democracia e a liberdade. Todo esse sistema de ideologias é parte de uma cotidianidade ingênua que manipula instrumentos."
} 
Central, Caribe, África, Ásia, dentre outras regiões.

Expressivamente, deve-se considerar a seguinte indagação: “É possível uma filosofia latino-americana, africana, asiática: do mundo periférico? [...] Tal discurso, para ser outro radicalmente, deve ter outro ponto de partida, deve pensar outros temas, deve chegar a diferentes conclusões e com método diferente" (DUSSEL, [1977], p. 176-177).

Ao demarcar os espaços de inserção destes pensamentos, geralmente obliterados, busca-se produzir locais de fala e de ação que transpareçam seus locais de origem, ao final proporcionar uma espécie de “justaposição dos saberes", ${ }^{12}$ isto é, a coexistência das múltiplas formas de conhecer não alicerçadas sectariamente no pensamento hegemônico. Mesmo porque, os povos latino-americanos possuem demandas específicas como, por exemplo, o processo de paz e transição com as Forças Armadas Revolucionárias da Colômbia - FARC, as questões indígenas, os conflitos agrários, as ditaduras civis-militares etc., quase sempre negligenciadas por leituras uniformizantes que desconsideram a multiplicidade impressa nas adjacências latino-americanas.

Tais cenários, permitem identificar que os centros hegemônicos pensam apenas parcela do mundo. Logo, ao volver outras interpretações possíveis para as formas de conceber os sentidos e as histórias acrescentar práticas distintas dos processos históricos realizados pela Europa e pelos EUA. Orientar a reprodução dos pensamentos conforme critérios de centralidade dos supostos centros de excelência, encerrada na ideia de que a França, na vanguarda dos processos políticos, a Inglaterra, na vanguarda industrial (econômica) e os EUA enquanto fusão de ambas. Produzem, como dito, um universalismo de partida que possui diferentes significações e reflexos.

Dimana do conjunto das reflexões até agora apresentadas a necessidade de compreensão sob distintos pontos de vista, por isso mesmo, não é defensável a manutenção de discursos hegemônicos que se renovam pela força de uma tradição que é repetida acriticamente. Equivale a dizer, que no para-

\footnotetext{
${ }^{12}$ Conforme conclusão apresentada por Dolores Cristina Gomes Galindo e Liliana Parra Valencia durante o minicurso: "Prácticas intelectuales indígenas, afrodiaspóricas y campesinas: decolonialidad del ser, del saber y del poder", em 01/11/2017, durante o XIX Encontro Nacional da Associação Brasileira de Psicologia Social - ABRAPSO, Democracia Participativa, Estado e Laicidade: Psicologia Social e enfrentamentos em tempos de exceção, realizado na Universidade Federal de Uberlândia - UFU, campus Santa Mônica, em Uberlândia, Minas Gerais, Brasil.
} 
digma democrático de direito não há espaço legítimo para as interpretações que potencialmente excluam outras formas ou sistemas de conhecer. De viva voz, lê-se em Bonavides (2001, p. 26), que na "Democracia onde o baixíssimo grau de legitimidade participativa certifica a farsa do sistema, assinalando o máximo divórcio entre o povo e as suas instituições de Governo."

Busca-se estabelecer interlocuções com outros estatutos epistemológicos para repensar o constitucionalismo brasileiro contemporâneo como uma tarefa epistemológica a ser realizada no contexto do "novo constitucionalismo democrático latino-americano (ou melhor, indo-afro-latino-americano)" (MAGALHÃES, 2016, p. 14). De fato, o chamado movimento pós-colonial ou decolonial procura tornar visíveis os sistemas de postulados e axiomas existentes nas outras partes do mundo, bem como suas tensões.

Contudo, ao se denunciar o projeto unilateral, não há como conjecturar um pensamento único extra europeu sob pena de reproduzir os mesmos equívocos que se quer evitar, ou seja, na dicotomia global/local perde-se de vista as agendas sociais emergentes ao propor uma transição única. Em verdade, nada mais são que idênticos resquícios de uma colonização cultural, política, filosoficamente construída. Talvez pelas mesmas razões, Martins, Morello e Tybusch (2017, p. 98), afirmam que as

[...] divergências históricas de suas realidades e inadequações suprime a capacidade desse modelo em satisfazer os anseios sociais, e, sobretudo, de efetivar os direitos humanos dos povos tradicionais, visto que, sufoca a diversidade, nega sujeitos em prol de uma identidade uníssona e uma igualdade formal forjada.

Estudar a associação entre uma "profilaxia epistemológica [...] permitindo que se construam novas categorias analíticas do pensar e agir" (LEAL, 2014, p. 242), e seus reflexos nos planos social e jurídico. Paradoxalmente esse discurso reivindicatório latino-americano é também encampado pelo lado europeu do mundo, a exemplo da "transição paradigmática" (SANTOS, 2001, p. 283).

Ao que tudo indica, não basta apenas ser produzido fora dos centros hegemônicos, pois, ainda, sim poderia simplesmente repetir o protocolo. De 
outra sorte, deve-se privilegiar as questões e pensamentos peculiares da América Latina, mesmo porque, "[...] um problema para um alemão do século XX ou um grego do século $\mathrm{V}$ a.C. pode, perfeitamente, não ser um problema para mim" (GOMES, 1994, p. 23).

De forma complementar, a possibilidade de se apresentar argumentos e contra-argumentos que dialoguem com a "diversidade teórico-filosófica" (DUSSEL, [1977], p. 212), certamente romperá com a linearidade histórica fundada na colonização do pensamento. Ao considerar a tarefa e responsabilidade do filósofo no processo de mudança, Dussel ([1977], p. 231), afirma que a "Compreensão da educação, da filosofia e da arte como instrumentos que aceleram, aprofundam e consolidam o processo de constituição de uma cultura popular autônoma."

Visto como condição para materializar o exercício da soberania popular positivada no parágrafo único, art. $1^{\circ}$, da Constituição da República Federativa do Brasil de 1988 - CRFB/ 88. Distinta, portanto, da mera reprodução do pensamento hegemônico. Ao se estabelecer relações capazes de incluir pensamentos não hegemônicos, cria-se diferentes graus de complexidades cujas manifestações são encaixadas nas categorias pré-existentes, sobretudo na paradoxal relação entre metrópole e colônia.

Toma-se de empréstimo as ideias de Santos (2010, p. 144), o qual sustenta que "[...] a diversidade e a pluralidade não tem ainda hoje uma expressão epistemológica adequada." Há, portanto, um "colonialismo intelectual" (RESTREPO; ROJAS, 2010, p. 198), que redunda no já mencionado efeito silenciador (avassalador) produzido e reproduzidos pelos discursos hegemônicos. Uma vez constatada essa problemática, apresenta-se como hipótese que "O lugar do crítico pós-colonial tem de ser construído de modo a que se possa interromper eficazmente os discursos hegemônicos ocidentais [...]" (SANTOS, 2010, p. 235).

Enquanto uma das várias respostas possíveis, Magalhães (2016, p. 18) sugere o "pluralismo epistemológico" como instrumento teórico. Por seu turno, Restrepo e Rojas (2010, p. 178, tradução nossa) ${ }^{13}$ afirmam que "A interculsectores subalternos en las disputas por el poder [...]" (RESTREPO; ROJAS, 2010, p. 178). 
turalidade seria, então, um projeto político e epistemológico que supõe uma participação ativa dos setores subalternos em disputa pelo poder [...]". Muito embora sejam relevantes, essas categorias abstratamente consideradas não são capazes de formar um estatuto que permita o adequado tratamento das questões apreciadas pelo controle concentrado de constitucionalidade brasileiro. Por isso, far-se-á uma incursão no sentido material da Constituição, manifestado pelas participações sociais, que emergem do giro epistemológico decolonial proposto.

\section{DESAFIOS E PERSPECTIVAS PARA O CONTROLE DE CONSTITUCIONALIDADE BRASILEIRO}

Dos tópicos pretéritos resta assentado o entendimento de que "O direito, como expressão cultural, não deve estar alheio as transformações sociais, devendo refletir os valores e princípios éticos indispensáveis à promoção da civilização mundial" (CAMBI, 2009, p. 78). E, o conceito material ou substantivo de Constituição possibilita conhecer os valores, culturas e modos de ser do povo, no sentido jurídico dos termos. Decerto, os pontos de vista são influenciáveis pelo local de fala de seus(suas) interlocutores(as).

Em que pese a Constituição da República de 1988 ser o atual repositório dos "valores materiais compartilhados pela sociedade" brasileira, conforme aduz Barroso (2012, p. 33) e, estar alicerçada na proteção e promoção da dignidade da pessoa humana (CRFB/88, art. $1^{\circ}$, III); estudos realizados por Oliveira (2016, p. 114), apontam para a prevalência do "estamento burocrático". Diante disso, o desafio que se impõe é manejar um arcabouço teórico capaz de fundamentar perspectivas democráticas com vistas a fortalecer as praxis latino-americanas.

Conforme se sabe, o controle de constitucionalidade é o conjunto de instrumentos jurídicos de aferição da conformidade de determinada lei ou ato normativo, que possui como parâmetro a Constituição vigente. Cujas matrizes sociológicas de formação foram a norte-americana, na espécie difusa e concreta; austríaca, na vertente concentrada e abstrata, ambas pela via repressiva judicial. Também existe o controle francês na modalidade política 
e, em regra, preventivo.

Não obstante as origens do controle de constitucionalidade, contemporaneamente exige-se a alteração do "solo epistemológico do direito" (CLÈVE, 1988, p. 34-47). Assim, o rearranjo proposto visa sugerir e analisar linhagens não convencionais de pensamentos, para ultrapassar as perspectivas universal e a-histórica, haja vista a prevalência destas visões. Por isso, as epistemologias hegemônicas refletem realidades, muitas das vezes, incompatíveis com a América Latina, sobretudo a enfrentada no Brasil, fortemente marcada por classes, estamentos e castas sociais (FAORO, 2012, p. 135).

Segundo afirma Lima (2011, p. 264), no Brasil vige o modelo híbrido ou misto de fiscalização da constitucionalidade das leis e atos normativos que, leva em consideração o objeto (ação ou omissão), o momento (preventivo ou repressivo), a natureza do órgão competente (jurídico ou político) e o modo de manifestação (objetivo ou subjetivo). Marca distintiva que, em um só tempo, contempla as três espécies de controle, todavia, em alguma medida, estes modelos privilegiaram a análise das condições formais, como já dito, a salvaguarda das "razões do Estado" (BORGES; CÂMARA; VILLAROEL, 2016, p. 138-164).

Em sua vertente concentrada é realizada pelo Supremo Tribunal Federal - STF, nos termos do art. 102, CRFB/88. Para conjugar os elementos trabalhados nos tópicos pretéritos, deve-se "[...] discutir alguns fundamentos e discursos de legitimidade do mecanismo de revisão judicial comuns especialmente nos países latinos, marcados por profundas desigualdades sociais e omissões legislativas" (CERQUEIRA NETO; SALGADO, 2016, p. 116).

Nesse sentido, cabe ilustrar de forma incisiva, tal qual o faz Cambi (2009, p. 285):

Não pode haver democracia se grande parte do eleitorado é analfabeto ou semiletrado, não tendo instrução necessária para compreender as principais questões colocadas no debate político, ou estão doentes e sem o adequado atendimento médico-hospitalar, ou se estão passando fome ou, ainda, se estão desempregadas ou trabalhando em condições opressivas. 
Por outros termos, revela-se contraproducente um controle de constitucionalidade que privilegia a análise formal ou a "arbitragem de conflitos políticos" (CAMBI, 2009, p. 209), que ao se enveredar numa racionalidade abstrata, torna-se incapaz de compreender os fenômenos sociais subjacentes, por consequência, perde de vista a situação concreta. Assim como afirmam Cerqueira Neto e Salgado (2016, p. 118), "São pressupostos de raiz conservadora, que diziam que se o que se pretendia era a tomada de decisões corretas, não era necessário consultar a cidadania de um modo efetivo." E, no caso em questão, fazer com que o controle de constitucionalidade desempenhe a função de assegurar as competências formais.

Ao depositarem as credenciais nas supostas virtudes individuais dos(as) "onze iluminados(as) supremos(as)", inegavelmente surge um amplo espaço para a atuação expressiva da atividade judicante solipsista. "Naturalmente, a nova postura de ativismo judicial do STF estimula as forças sociais a procurá-lo com mais frequência e contribui para uma significativa alteração na agenda da Corte" (SARMENTO, 2009, p. 130-131). No entanto, estudos atualizados constatam a prevalência das "burocracias do Estado" em detrimento dos direitos fundamentais e sociais, como é o caso das questões relacionadas ao "trabalho, educação, saúde, moradia, entre outros" (OLIVEIRA, 2016, p. 129). No mesmo sentido Cerqueira Neto e Salgado (2016, p. 122-123), sustentam, com maior precisão, que:

Frequentemente se argumenta que o tribunal atua como defensor das minorias. Mas isto não é necessariamente correto. Este discurso é bastante aceito em defesa da supremacia judicial, sobretudo em países marcados por profundas desigualdades sociais, como nas recentes democracias da América Latina.

Ao contrário de implementar e avançar na interpretação aberta e plural, principalmente do ponto de vista epistêmico, conforme mencionado nos tópicos antecedentes, o controle de constitucionalidade brasileiro parece insistir nas práticas contrárias. "O que não parece ter assento constitucional é o forte ativismo constitucional, por vezes francamente contrário à própria 
Constituição" (CERQUEIRA NETO; SALGADO, 2016, p. 115). Outro aspecto deficitário a ser destacado é que

O STF não profere uma fundamentação da corte em suas decisões, mas decide a partir de um apanhado de votos individuais, que geralmente já chegam prontos à sessão de julgamento. Não há deliberação, não há construção coletiva das decisões, não há clareza para além do dispositivo (quando muito). A corte brasileira se preocupa mais com o resultado que com a fundamentação de cada caso. (CERQUEIRA NETO; SALGADO, 2016, p. 119).

Para ilustrar, "Naturalmente, a decisão tomada (sobretudo sua fundamentação) poderá ser diferente para cada concepção de democracia que o tribunal subscreva" (CERQUEIRA NETO; SALGADO, 2016, p. 120). Isto porque, as teorias hegemônicas parecem cumprir uma função bastante específica nesse ínterim, que é o distanciamento do material fático que subjaz a determinada lei ou ato normativo, ainda que abstratamente considerados.

De outro modo, é o fundamento que orienta o dispositivo e, não o inverso. Pois, a razão de decidir (ratio decidendi) reside na fundamentação substantiva e suficiente, guiada pelos elementos fáticos e jurídicos desvelados na apreciação da situação analisada. Como não preponderam a atividade inclusiva de outros(as) sujeitos(as), nem a atividade deliberativa entre os(as) Ministros(as) do STF, mas apenas a contagem dos votos individuais suprema e soberanamente prolatados, surge espaço para que as decisões sejam marcadas, em sua ampla maioria, de baixa densidade democrática.

Em alguma medida os desafios enfrentados pelo controle de constitucionalidade brasileiro, a partir do panorama traçado, permitem inferir alguma aproximação com a colonialidade do pensamento ilustrada acima. Isto porque, o sectarismo epistemológico somado ao desconhecimento de outros saberes, sem exageros, aproxima-se da prevalência da técnica, conhecimento de uns poucos, e o insistente solipsismo judicial.

Realizadas estas aproximações, entende-se que para emergir a realidade do sentido material da Constituição e, consequentemente, os pensamen- 
tos latino-americanos parece adequado ilustrar com a filosofia da libertação. Cuja sugestão de inserção no espaço público institucional são as intervenções dos amici curiae e as audiências públicas, entre outras possíveis. Dussel ([1977], p. 07) esclarece tratar-se de uma obra escrita na e para a periferia, contudo, dirige-se, também, para o centro. Com algumas reservas, ${ }^{14}$ endossa-se seu posicionamento no que toca ao apontar para caminhos futuros.

Para se fazer manifesto, os desafios enfrentados pelo controle de constitucionalidade na atualidade, em alguma medida, são as consequências dos reflexos da geopolítica de imposição da "cultura do centro" (DUSSEL, [1977], p. 10). Há, nitidamente, a hegemonia da insistente forma de "pensar" que "Fora de suas fronteiras está o não-ser, o nada, a barbárie, o sem sentido" (DUSSEL, [1977], p. 11). Ou seja, as questões de ordem social e fundamental devem ser enfrentadas por outros mecanismos que não apenas os judiciais, ao contrário, nestas preponderam outras questões.

Em outras palavras "a partir do centro interpretam a periferia. Mas os filósofos coloniais da periferia repetem uma visão que lhes é estranha, que não lhes é própria" (DUSSEL, [1977], p. 19). Apesar disso, não está dito que se deva excluir por completo, pois, quando a chamada periferia existe enquanto exótico ou colônia. Vê-se nas entrelinhas, se tratar de uma perspectiva de (re) leitura das bases teóricas e epistêmicas da forma de compreensão do controle concentrado de constitucionalidade brasileiro.

Sobretudo na realidade brasileira contrastada por acentuada desigualdade social e pela não implementação de direitos básicos do ser humano; quando se busca, ainda que consciente das limitações e das dificuldades, aplicar conhecimentos originários de países que possuem realidades materiais assemelhadas quer-se, em última, análise " [...] romper os laços de dependência dominadora" (DUSSEL, [1977], p. 80). Pois,

O cientista que não consegue articular o exercício de sua ciência com os condicionamentos efetivos e dialéticos da política, descobrir sua autonomia relativa, e que não sabe ou-

${ }^{14}$ Dentre outras, a objeção apresentada por Pazello (2016, p. 197), segundo o qual o termo "filosofia da libertação" é uma redundância. 
vir claramente as interpelações que o povo oprimido lança contra o sistema, é um cientificista. (DUSSEL, [1977], p. 172, grifo do autor).

No caso da jurisdição constitucional, em sentido estrito, não deve ancorar-se exclusivamente no "fundamento" de validade ou superioridade do Texto Constitucional, desconectado do substrato fático ou social analisado, ainda que se trade de lei ou ato jurídico em tese. Em última análise, outras epistemologias potencialmente proporcionam "Ao mesmo tempo em que são forças materiais da sociedade que impõem limites e se opõem à falta de controle da arbitragem, são também elementos de revolução jurídica, modificação e mudança constitucional" (BORGES, et. al, 2017, p. 529, tradução nossa). ${ }^{15}$

E como a proposta de guinada epistemológica para o Sul busca-se, no mínimo, chegar a resultados diferentes do até agora obtidos, caberia, então, falar sobre "A hermenêutica diatópica é um exercício de reciprocidade entre culturas que consiste em transformar as premissas de argumentação de uma dada cultura em argumentos inteligíveis e creditáveis noutra cultura." (SANTOS, 2010, p. 87).

Numa ligeira demonstração sobre como a construção dos parâmetros materiais de conformidade com as realidades sociais experimentada pela América Latina, fornecem respostas não comportadas pelos padrões hegemônicos tradicionais, fala-se sobre a inserção de novos(as) agentes mediante o reconhecimento dos direitos de participação cidadã. Tem-se, portanto, outras formas da função judicial a exemplo das positivadas na Constituição da República do Equador ${ }^{16}$ cujos objetivos propostos para este artigo impedem descer as minúcias desse argumento.

\section{CONSIDERAÇÕES FINAIS}

Esse artigo teve por objetivo apresentar uma fundamentação teórica destinada a inclusão de epistemologias não hegemônicas, isto é, não produ-

\footnotetext{
${ }^{15}$ No original: "Al mismo tiempo que son fuerzas materiales de la sociedad que imponen límites y se contraponen al descontrol del arbitrio, son también los elementos de revolución jurídica, modificación y mutación constitucional." (BORGES, et. al, 2017, p. 529).

${ }^{16}$ Cf. Título IV, Capítulo cuarto, Función Judicial y justicia indigena (ECUADOR, 2008).
} 
zidas ou destinadas para os eixos tradicionais de elaboração do pensamento ocidental. Tais reflexões foram destinadas à aplicação no controle de constitucionalidade concentrado brasileiro, com vistas a (re)ordenar os discursos socialmente construídos para encurtar as distâncias entre os fundamentos teóricos e o campo prático de atuação.

Portanto, fez-se necessário observar a tradição democrática segundo uma nova geopolítica epistemológica, fato que não implica uma "eurocentricidade" às avessas, ao contrário, pretende-se de forma aproximativa, dialogar com os espaços de realização de outras epistemologias, pautado em concepções não hegemônicas.

Numa espécie de prestação de contas, viu-se no segundo tópico a constatação de um fenômeno caracterizado pelo sectarismo epistemológico, com pretensão de exclusividade, universalidade e atemporalidade. A colonialidade do saber que ignora ou desconsidera qualquer outro saber que não sejam aqueles dominantes; em alguma medida, (de)formam os pensamentos latino-americanos.

Em seguida, no terceiro tópico, a pesquisa cuidou de examinar alguns dos pensamentos latino-americanos como possível paradigma de desconstrução histórica da situação-problema constatada. Sob o pano de fundo de uma racionalidade democrática e inclusiva, buscou-se franquear as participações de outras epistemologias, enquanto forma de conhecer e, assim, permitir a interrelação entre os pensamentos produzidos na América Latina.

Diante disso, a partir de um plano mais específico, o resultado das pesquisas bibliográficas constatou a prevalência das "razões do Estado" na pauta de debate do controle concentrado de constitucionalidade brasileiro. De certa maneira, devido à reprodução da problemática constatada no primeiro tópico. Logo, pelas análises dos materiais coletados é possível apresentar como consideração final a necessidade de romper com a dicotomia "metrópole/colônia", mediante a inserção de outros(as) agentes, teorias e lugares, eufemisticamente chamado de "epistemologias do Sul", que como visto perpassa e ultrapassa as cercanias da América Latina.

Enfim, implica privilegiar o aspecto material da Constituição somado as compreensões culturais do direito na interpretação/aplicação das questões 
levadas até o conhecimento do controle de constitucionalidade que, como já dito, deve privilegiar os temas dos direitos e das garantias fundamentais. Vale reforçar, uma vez mais, que a tese esboçada não significa o "eurocentrismo as avessas", mas, de outra sorte, o esforço de direcionar os olhares para pessoas, teorias e lugares geralmente olvidados.

\section{REFERÊNCIAS}

BARROSO, Luís Roberto. O controle de constitucionalidade no direito brasileiro: exposição sistemática da doutrina e análise crítica da jurisprudência. 6. ed. rev. e atual. São Paulo: Saraiva, 2012.

BERTHET, Annie. et. al. Alter ego plus: méthode de français. Paris : Hachette Livre, 2012.

BONAVIDES, Paulo. Teoria constitucional da democracia participativa. Por um direito constitucional de luta e resistência. Por uma nova Hermenêutica. Por uma repolitização da legitimidade. São Paulo: Malheiros, 2001.

BORGES, Alexandre Walmott; CÂMARA, Fabiana Angélica Pinheiro; VILLAROEL, Ivette Esis. O sistema de controle de constitucionalidade brasileiro: entre a tutela de direitos e a tutela do ordenamento. In: ROBL FILHO, Ilton Norberto; SCHELEDER, Adriana Fasolo Pilati. (Org.). Jurisdição constitucional e democracia. Itajaí: UNIVALI, 2016, p. 138-164.

BORGES, Alexandre Walmott. et. al. Un balance de los sistemas de control de constitucionalidad como instrumento de garantía de las constituciones material y formal. Revista Estudos Institucionais - REI, Rio de Janeiro, v. 03, n. 01, 2017, p. 525- 561.

BRASIL. Constituição (1988). Constituição da República Federativa do Brasil. Brasília: Senado, 1988.

CAMARGO, Luís Henrique Kohl; GABIATTI, Daniel Albherto; MELLO, Régis Trindade de. Do eurocentrismo à libertação: o papel da teoria crítica do direito na construção de um pensar jurídico autêntico latino-americano. Unoesc International Legal Seminar, Chapecó, v. 02, n. 01, 2013, p. 423-446. 
CAMBI, Eduardo. Neoconstitucionalismo e neoprocessualismo: direitos fundamentais, políticas públicas e protagonismo judiciário. São Paulo: Revista dos Tribunais, 2009.

CÁRCOVA, Carlos María. A opacidade do direito. Tradução de Edilson Alckmin Cunha. São Paulo: LTr, 1998.

CERQUEIRA NETO, José Nunes de; SALGADO, Eneida Desiree. Caminhos e desafios da revisão judicial de constitucionalidade. Revista de direitos fundamentais $e$ democracia, Curitiba, v. 19, n. 19, jan./jun. 2016, p. 114-130.

CLÈVE, Clèmerson Merlin. O direito e os direitos: elementos para uma crítica do direito contemporâneo. São Paulo: Scientia et Labor, 1988.

DUSSEL, Enrique Domingo. Ética da libertação: na idade da globalização e da exclusão. Petrópolis: Vozes, 1998.

DUSSEL, Enrique Domingo. Filosofia da libertação na América Latina. Tradução de Luiz João Gaio. São Paulo: Loyola, [1977]. (Reflexão latino-americana n. 3).

ECUADOR. Constitución (2008). Constitución de la República del Ecuador. Quito: Registro Oficial, 2008. Disponible en: <www.lexis.com.ec>. Acceso en: 29 nov. 2017.

FAGUNDES, Lucas Machado; WOLKMER, Antonio Carlos. Pluralismo jurídico no horizonte do pensamento crítico de libertação latino-americana. A reflexão crítica no contexto latino-americano. In: BENENTE, Mauro; RAJLAND, Beatriz. (Coord.). El Derecho y el Estado: procesos políticos y constituyentes en nuestra América. Ciudad Autónoma de Buenos Aires: Fundación de Investigaciones Sociales y Políticas, 2016, p. 63-81.

FAORO, Raymundo. Os donos do poder: formação do patronato político brasileiro. 5 . ed. São Paulo: Globo, 2012.

FIGUEIREDO, Ângela. Descolonização do conhecimento no século XXI. In: SANTIAGO, Ana Rita. et al. (Org.). Descolonização do conhecimento no contexto afro-brasileiro. Cruz das Almas: UFRB, 2017, p. 79-106.

FISS, Owen M. A ironia da liberdade de expressão: Estado, regulação e diversidade na esfera pública. Tradução e prefácio de Gustavo Binenbojm e Caio Mário da Silva Pereira Neto. Rio de Janeiro: Renovar, 2005.

GADAMER, Hans-Georg. Verdade e método I: traços fundamentais de uma hermenêutica filosófica. Tradução de Flávio Paulo Meurer e Enio Paulo Giachini. 15. ed. Petrópolis: Vozes, 2015, v. 1 (Pensamento humano). 
GODOY, Miguel Gualano de. A democracia deliberativa como guia para a tomada de decisões legítimas. Análise teórica a partir de Carlos Santiago Nino e algumas práticas institucionais no Brasil contemporâneo. Revista Co-herencia, Medellín, v. 08, n. 14, ene./jun. 2011, p. 63-91.

GODOY, Miguel Gualano de. Constitucionalismo e democracia: uma leitura a partir de Carlos Santiago Nino e Roberto Gargarella. São Paulo: Saraiva, 2012. (Direito, Desenvolvimento e Justiça).

GODOY, Miguel Gualano de; KOZICKI, Katya. A democracia deliberativa para além de John Rawls e Jürgen Habermas e a proposta de Carlos Santiago Nino. In: CLÈVE, Clèmerson Merlin. (Coord.). Direito constitucional brasileiro: teoria da constituição e direitos fundamentais. São Paulo: Revista dos Tribunais, 2014, p. 1.106-1.124, v. 1.

GOMES, Roberto. Crítica da razão tupiniquim. 11. ed. São Paulo: FTD, 1994. (Prazer em conhecer).

GÜVEN, Ferit. Decolonizing democracy: intersections of philosophy and postcolonial theory. London: Lexington Books, 2015.

HÄBERLE, Peter. La sociedad abierta de los intérpretes constitucionales una contribución para la interpretación pluralista y "procesal" de la constitución. Traducción Xabier Arzoz Santisteban. Contextos, Ciudad Autónoma de Buenos Aires, n. 05, abr. 2013, p. 63-88.

LEAL, Sandra Regina. A reversão da eurocentricidade conceitual dos direitos humanos a partir da sua tropicalização com a Constituição Federal de 1988. In: CLĖVE, Clèmerson Merlin. (Coord.). Direito constitucional brasileiro: teoria da constituição e direitos fundamentais. São Paulo: Revista dos Tribunais, 2014, p. 228-244, v. 1.

LIMA, Bruno Sousa de. Entre Constituição e democracia: uma análise do controle de constitucionalidade brasileiro. In: CLĖVE, Clèmerson Merlin. (Coord.). Constituição, democracia e justiça: aportes para um constitucionalismo igualitário. Belo Horizonte: Fórum, 2011, p. 263-284.

MAGALHÃES, José Luiz Quadros de. O novo constitucionalismo latino-americano 2: rupturas diversidade. Revista Eletrônica de Direito do Centro Universitário Newton Paiva, Belo Horizonte, n. 28, jan./abr. 2016, p. 10-19.

MARTINS, Evilhane Jum; MORELLO, Giane da Silva Ritter; TYBUSCH, Jerônimo Siqueira. As amarras do neoconstitucionalismo e as perspectivas do novo constitucionalismo Latino-americano: elementos paradigmáticos para a efetivação dos direitos humanos dos povos da América do Sul. Revista de Direito Brasileira, São Paulo, v. 17 , n. 07 , maio/ago. 2017, p. 90-107. 
MONTERO, Julio. La concepción de la democracia deliberativa de C. Nino: ¿populismo moral o elitismo epistemológico? DOXA, Cuadernos de Filosofía del Derecho, Alicante, n. 29, 2006, p. 319-331.

OLIVEIRA, Fabiana Luci de. Agenda Suprema: interesses em disputa no controle de constitucionalidade das leis no Brasil. Tempo Social, São Paulo, v. 28, 2016, p. 105-133. Disponível em: <http://www.scielo.br/pdf/ts/v28n1/1809-4554-ts-28-01-00105. pdf>. Acesso em: 10 abr. 2017.

OLIVEIRA, Wagner Vinicius de. Amici curiae e legitimidade: sobre as participações das instituições religiosas no controle concentrado de constitucionalidade brasileiro. 2018. 162 f. Dissertação (Mestrado). Universidade Federal de Uberlândia - UFU, Faculdade de Direito "Prof. Jacy de Assis", Programa de Pós-Graduação em Direito. Uberlândia, 2018.

OLIVEIRA, Wagner Vinicius de. Constitucionalismo contemporâneo: a relação entre as emendas constitucionais e as novas respostas da democracia participativa. Revista Libertas. Direito UFOP, Ouro Preto, v. 03, n. 02 fev./mar. 2018, p. 148-170. OLIVEIRA, Wagner Vinicius de. Resenha. FISS, Owen M. A ironia da liberdade de expressão: Estado, regulação e diversidade na esfera pública. Tradução e prefácio de Gustavo Binenbojm e Caio Mário da Silva Pereira Neto. Rio de Janeiro: Renovar, 2005. Revista da Faculdade de Direito (UFU), v. 44, 2016, p. 01-05.

OLIVEIRA, Wagner Vinicius de; SOUSA, Jaqueline Aparecida Fernandes. Epistemologias do sul aplicada ao controle concentrado de constitucionalidade brasileiro. In: BUSTAMANTE, Thomas da Rosa de. et al. (Coord.). Anais do III Congresso de Direito Constitucional e Filosofia Política: a desigualdade e a reconstrução da democracia social. [Caderno de resumos]. Belo Horizonte: Arraes, 2017, p. 177-179.

PAZELLO, Ricardo Prestes. Pensamiento descolonial, crítica al derecho, movimientos populares: la problemática de los derechos humanos. Revista de Derechos Humanos y Estudios Sociales - REDHES, México, n. 15, año VIII, ene./jun. 2016, p. 195-218.

PULIDO, Carlos Bernal. Sobre a legitimidade da jurisdição constitucional e a objetividade no controle de constitucionalidade das leis. In: PULIDO, Carlos Bernal. (Coord.). Direitos dos direitos: escritos sobre a aplicação dos direitos fundamentais. Tradução de Thomas da Rosa de Bustamante. São Paulo: Marcial Pons, 2013, p. 29-58.

RESTREPO, Ricardo; ROJAS, Axel. Inflexión decolonial: fuentes, conceptos y cuestionamientos. Popayán: Universidad del Cauca, 2010. (Políticas de la alteridad).

SANTOS, Boaventura de Souza. A gramática do tempo: para uma nova cultura política. 3. ed. São Paulo: Cortez, 2010, v. 4. (Para um novo senso comum). 
SANTOS, Boaventura de Souza. Para além do pensamento abissal: das linhas globais a uma ecologia de saberes. In: MENEZES, Maria Paula; SANTOS, Boaventura de Souza. (Orgs.). Epistemologias do sul. Coimbra: Almedina, 2009, p. 23-72.

SANTOS, Boaventura de Souza. Pela mão de Alice: o social e o político na pós-modernidade. 8. ed. São Paulo: Cortez, 2001.

SARMENTO, Daniel. O neoconstitucionalismo no Brasil: riscos e possibilidades. In: SARMENTO, Daniel. (Coord.). Filosofia e teoria constitucional contemporânea. Rio de Janeiro: Lumen Iuris, 2009, p. 113-146.

SILVA, Heleno Florindo da. O novo constitucionalismo plurinacional na América do Sul e a noção de "unidade do povo" na obra O Guardião da Constituição, de Carl Schmitt: um diálogo entre diferentes para uma construção intercultural dos direitos humanos. In. BARROS, Flaviane de Magalhães; MACHADO, Felipe Daniel Amorim. (org.). Anais do $5^{\circ}$ Congresso de Constituição e Processo: hermenêutica e jurisdição constitucional. Belo Horizonte: Initia Via, 2013, p. 218-249. 